\title{
An enhanced damage plasticity model for predicting the cyclic behavior of plain concrete under multiaxial loading conditions
}

\author{
Mohammad Reza AZADI KAKAVAND ${ }^{a^{*}}$, Ertugrul TACIROGLU ${ }^{b}$ \\ ${ }^{a}$ Unit of Strength of Materials and Structural Analysis, Institute of Basic Sciences in Engineering Sciences, University of Innsbruck, \\ Innsbruck 6020, Austria \\ ${ }^{b}$ Department of Civil \& Environmental Engineering, University of California, Los Angeles, CA 90095, USA \\ *Corresponding author. E-mail: mohammadreza.azadi86@gmail.com
}

(C) The Author(s) 2020. This article is published with open access at link.springer.com and journal.hep.com.cn

\begin{abstract}
Some of the current concrete damage plasticity models in the literature employ a single damage variable for both the tension and compression regimes, while a few more advanced models employ two damage variables. Models with a single variable have an inherent difficulty in accounting for the damage accrued due to tensile and compressive actions in appropriately different manners, and their mutual dependencies. In the current models that adopt two damage variables, the independence of these damage variables during cyclic loading results in the failure to capture the effects of tensile damage on the compressive behavior of concrete and vice-versa. This study presents a cyclic model established by extending an existing monotonic constitutive model. The model describes the cyclic behavior of concrete under multiaxial loading conditions and considers the influence of tensile/compressive damage on the compressive/tensile response. The proposed model, dubbed the enhanced concrete damage plasticity model (ECDPM), is an extension of an existing model that combines the theories of classical plasticity and continuum damage mechanics. Unlike most prior studies on models in the same category, the performance of the proposed ECDPM is evaluated using experimental data on concrete specimens at the material level obtained under cyclic multiaxial loading conditions including uniaxial tension and confined compression. The performance of the model is observed to be satisfactory. Furthermore, the superiority of ECDPM over three previously proposed constitutive models is demonstrated through comparisons with the results of a uniaxial tension-compression test and a virtual test.
\end{abstract}

KEYWORDS damage plasticity model, plain concrete, cyclic loading, multiaxial loading conditions

\section{Introduction}

Numerous experimental and numerical studies have been performed to develop, calibrate, and validate predictive response models for plain and reinforced concrete in structural systems under seismic loading [1-13]. While some of these studies have focused on the development of phenomenological models to capture structural-level behavior (e.g., in beams and columns), there have also been efforts to establish models at the continuum level [14-22]. Such models enable more accurate predictions of

Article history: Received Oct 8, 2019; Accepted Nov 10, 2019 the concrete behavior and its interactions with reinforcement, and allow researchers to better examine and understand the structural response.

Models based on observations or measurements made under only monotonic loading cannot reflect various key characteristics that reinforced concrete members exhibit under cyclic loading, such as the opening and closing of cracks and the cracking patterns [18-22]. Numerous constitutive models for concrete behavior at the material and structural member scales have been proposed in the literature [23-30]. A portion of these models merely describe the uniaxial behavior of plain unconfined $[14,15,31-33]$ or confined $[14,16,17,34-39]$ concrete. 
The confinement is typically provided by transverse reinforcement, which improves the ultimate strength and ductility of the concrete.

Constitutive models for simulating the behavior of concrete under cyclic and dynamic loads have also been proposed. While various capabilities of these models have been demonstrated, uncertainties on their ability to predict the cyclic behavior of concrete still remain. Some of these models are briefly reviewed next, and a particular key shortcoming of the two most advanced models is discussed to provide context for the model that will be proposed herein.

Bićanić and Zienkiewicz [40] proposed a constitutive model for analyzing plain concrete structures under dynamic loading conditions. The model follows Perzyna's theory of elasto-viscoplasticity [41]. Suaris and Shah [42] presented a constitutive model based on continuum damage mechanics to predict the nonlinear biaxial tension-compression behavior of concrete under dynamic loading. Rabczuk and Eibl [43] proposed a numerical model to capture the effects of large dynamic loading conditions and large deformations on concrete failure. Sima et al. [44] developed a constitutive model for concrete that describes the strength and stiffness degradation for both compression and tension using two independent damage variables for the said behavior regimes. The model also describes the opening and closing of cracks under uniaxial cyclic loading. He et al. [45] proposed a constitutive model based on the smeared rotating crack approach to capture the cyclic behavior of concrete, including inelastic strains, crack opening and closing, and the degradation of its strength and stiffness. Tasnimi and Lavasani [46] developed a nonlinear constitutive model for the uniaxial cyclic behavior of plain and reinforced concrete elements based on the elastoplastic-fracture-damage (EPFD) theory using one parameter for the damage due to compression and another parameter for the fracture under tension. Breccolotti et al. [47] enhanced the constitutive model of Sima et al. [44], which has not considered the damage accumulation during unloading. Moharrami and Koutromanos [48] formulated a constitutive model to simulate the cyclic behavior of concrete by combining classical plasticity with the smeared-crack model. Huguet et al. [49] proposed a constitutive model for reinforced concrete members. The model explicitly considers crushing under compression, cracking under tension, bond slip between concrete and rebars, and steel yielding at crack-crossing.

A number of numerical studies have investigated cracking in concrete at both the material and structural levels and presented 2D/3D meshfree approaches for modeling arbitrary crack initiation, crack growth, and discrete cracks [50-53]. Some recent studies include the assessment of fractures in various materials using a dualhorizon peridynamics method for fractures in granular and rock-like materials [54,55]; a phase field model for fractures in 2D/3D continua in homogeneous and heterogeneous materials [56]; self-propagating strong-discontinuity embedded and cracking-element methods for quasibrittle [57] and dynamic fractures [58], respectively; and a robust discontinuity-embedded approach for fractures in quasi-brittle materials such as glass and concrete [59].

Among the proposed models for concrete, one particular model has arguably found the most practical use in simulating the cyclic behavior of concrete at both the material and structural member scales. This model, which was proposed by Lee and Fenves [60], combines the classical plasticity and continuum damage mechanics approaches, and is typically referred to as the concrete damage plasticity model (CDPM). CDPM is able to account for the stiffness degradation and strength recovery due to the opening and closing of cracks, as well as the effects of low levels of lateral confinement on the strength and ductility. A more recent multi-axial model (henceforth CDPM2) was proposed by Grassl et al. [61] as an improvement over the CDPM1 proposed by Grassl and Jirásek [29] for monotonic loading. CDMP2 aims to capture the increase in the load-carrying capacity with increasing confinement, as well as the transition between the tension and compression regimes through the use of two damage variables [61]. Despite their advanced features, neither CDPM, nor the more advanced CDPM2, can describe the influence of prior compressive/tensile damage on the tensile/compressive behavior. This particular shortcoming is addressed in the present study through the development of a new model, namely the enhanced concrete damage plasticity model (henceforth, the ECDP model or ECDPM), that aims to capture the behavior of plain concrete under cyclic multiaxial loading conditions. The latter is one of the advantages of ECDPM over the two prior cyclic damage plasticity models [60,61] whose abilities to predict the cyclic response of plain concrete under biaxial and triaxial cyclic compression conditions have neither been demonstrated nor examined in the open literature.

\section{An enhanced damage plasticity model for concrete}

The proposed new ECDPM is an enhanced version of the damage plasticity model proposed by Grassl et al. [29,61]. Its features include isotropic hardening and softening, the generation and accumulation of inelastic strains, as well as stiffness degradation due to damage in both the compressive and tensile regimes. The nominal stress-strain relationship in ECDPM takes the form

$$
\boldsymbol{\sigma}=(1-D) \boldsymbol{E}_{0}:\left(\boldsymbol{\varepsilon}-\boldsymbol{\varepsilon}^{\mathrm{P}}\right),
$$

where $\sigma$ denotes the nominal stress tensor, $D$ is the scalar isotropic damage variable ranging from 0 (undamaged concrete) to 1 (fully damaged concrete), $\boldsymbol{E}_{0}$ is the initial 
elastic stiffness tensor, and $\varepsilon$ and $\varepsilon^{\mathrm{p}}$ are the total and plastic strain tensors, respectively. The plastic part of the model is formulated in terms of the effective stress, which is defined as

$$
\overline{\boldsymbol{\sigma}}=\frac{\boldsymbol{\sigma}}{(1-D)} .
$$

The model takes the softening in the post-peak region caused by crushing under compression or cracking under tension into account by splitting the damage variable $(D)$ into two damage variables in the two regimes as follows:

$$
(1-D)=\left(1-D_{\mathrm{c}}\right)\left[1-r_{\mathrm{w}} D_{\mathrm{t}}\right]
$$

where $D_{\mathrm{c}}$ and $D_{\mathrm{t}}$ denote the scalar isotropic damage variables under compression and tension, respectively. The split weight factor $r_{\mathrm{w}}$ ranges from 0 (purely $3 \mathrm{D}$ compressive strain state) to 1 (total tension) and is defined as [62]

$$
r_{\mathrm{w}}=\frac{\sum_{I=1}^{3}\left\langle\varepsilon_{I}\right\rangle}{\sum_{I=1}^{3}\left|\varepsilon_{I}\right|},
$$

where $\left\langle\varepsilon_{I}\right\rangle$ is the positive part of the principal strain component $\varepsilon_{I}$ and $I=1,2,3$ [62]. Other damage plasticity models employ a stress-based split weight factor [60,61].

The effects of various split weight factors on the cyclic response of plain concrete in ECDPM and the other two damage plasticity models considered herein (i.e., CDPM by Lee and Fenves [60] and CDPM2 by Grassl et al. [61]) are shown in Fig. 1. It can be observed from Fig. 1(a) that the material experiences tensile damage $\left(D_{\mathrm{t}}>0\right)$, which results in the reduction of tensile stiffness. However, because the loading direction varies when the stress enters into the compressive regime $\left(D_{\mathrm{c}}=0\right)$, the value of the stiffness suddenly changes to its intact value because of the stress-based split weight factor. It is worth noting that Grassl et al. [61] proposed a bilinear model for tensile softening. The present study uses the exponential tensile softening response proposed in Ref. [29]. Figure 1(b) demonstrates the influence of the strain-based split weight factor on the stress-strain response and the compressive stiffness. It can be observed in Fig. 1(b) that the tensile damage causes a reduction of the compressive stiffness. The employment of a strain-based split weight factor is one of the main differences between ECDPM and the other damage plasticity models $[60,61]$.

The elastic domain is delimited by employing a single yield surface $f_{\mathrm{p}}$ formulated in the Haigh-Westergaard coordinates of the effective stress tensor [29]:

$$
\begin{gathered}
f_{\mathrm{p}}\left(\bar{\sigma}_{\mathrm{m}}, \bar{\rho}, \theta, q_{\mathrm{h}}\right)=\left(\left(1-q_{\mathrm{h}}\right)\left(\frac{\bar{\rho}}{\sqrt{6} f_{\mathrm{cu}}}+\frac{\bar{\sigma}_{\mathrm{m}}}{f_{\mathrm{cu}}}\right)^{2}+\sqrt{\frac{3}{2}} \frac{\bar{\rho}}{f_{\mathrm{cu}}}\right)^{2} \\
+m_{0} q_{\mathrm{h}}^{2}\left(\frac{\bar{\rho}}{\sqrt{6} f_{\mathrm{cu}}} r(\theta)+\frac{\bar{\sigma}_{\mathrm{m}}}{f_{\mathrm{cu}}}\right)-q_{\mathrm{h}}^{2}
\end{gathered}
$$

The effective mean stress $\bar{\sigma}_{\mathrm{m}}$, the effective deviatoric radius $\bar{\rho}$, and the Lode angle $\theta$ are three invariants of the effective stress tensor; $f_{\text {cu }}$ is the uniaxial compressive strength of concrete; $m_{0}$ is a frictional model parameter; $r(\theta)$ is a function describing the shape of the yield surface in the deviatoric planes [23]; and $q_{\mathrm{h}}$ denotes a stress-like internal hardening variable. The evolution of the yield surface in the principal stress space during hardening is illustrated in Fig. 2.

The evolution of the plastic strain is given by

$$
\dot{\boldsymbol{\varepsilon}}^{\mathrm{P}}=\dot{\lambda} \frac{\partial g_{\mathrm{p}}\left(\bar{\sigma}_{\mathrm{m}}, \bar{\rho}, q_{\mathrm{h}}\right)}{\partial \overline{\boldsymbol{\sigma}}}=\dot{\lambda} \mathbf{m}
$$

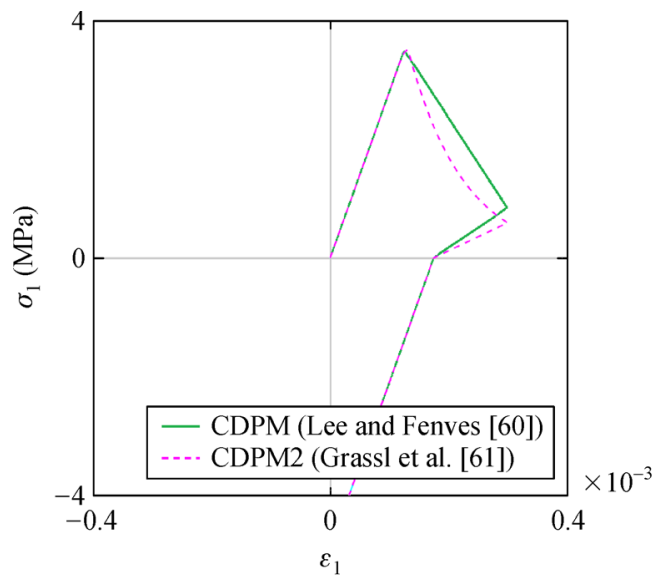

(a)

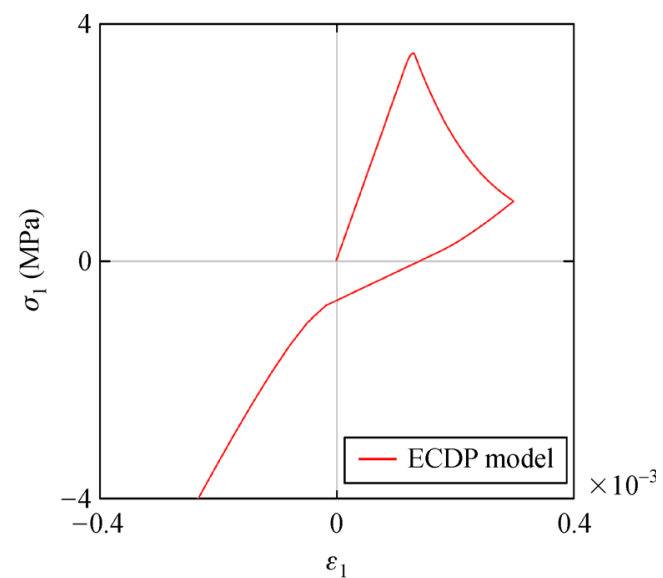

(b)

Fig. 1 The influence of the split weight factor on the cyclic behavior of plain concrete during the transition from tensile to compressive loading: (a) stress-based split weight factor employed in damage plasticity models by Lee and Fenves [60] and Grassl et al. [61]; (b) strainbased split weight factor employed in ECDPM. 


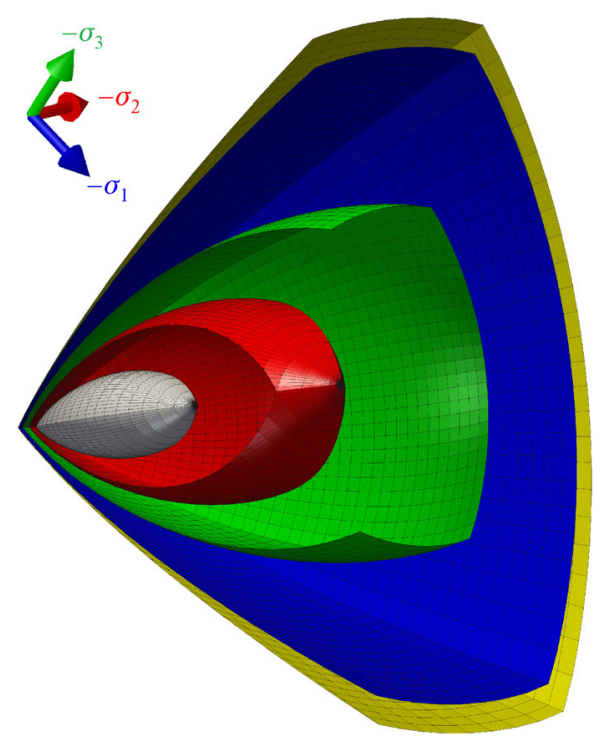

Fig. 2 Evolution of the yield surface during hardening.

where $\dot{\lambda}$ is the consistency parameter, and $g_{\mathrm{p}}$ is the nonassociated plastic potential function, which is defined as [29]

$$
\begin{aligned}
& g_{\mathrm{p}}\left(\bar{\sigma}_{\mathrm{m}}, \bar{\rho}, q_{\mathrm{h}}\right) \\
& =\left(\left(1-q_{\mathrm{h}}\right)\left(\frac{\bar{\rho}}{\sqrt{6} f_{\mathrm{cu}}}+\frac{\bar{\sigma}_{\mathrm{m}}}{f_{\mathrm{cu}}}\right)^{2}+\sqrt{\left.\frac{3}{2} \frac{\bar{\rho}}{f_{\mathrm{cu}}}\right)^{2}}\right. \\
& \quad+q_{\mathrm{h}}^{2}\left(\frac{m_{0} \bar{\rho}}{\sqrt{6} f_{\mathrm{cu}}}+\frac{m_{\mathrm{g}}\left(\bar{\sigma}_{\mathrm{m}}\right)}{f_{\mathrm{cu}}}\right),
\end{aligned}
$$

where $m_{\mathrm{g}}\left(\bar{\sigma}_{\mathrm{m}}\right)$ controls the ratio of the volumetric and deviatoric parts of the flow direction. It is a function of the effective mean stress and takes the form

$$
m_{\mathrm{g}}\left(\bar{\sigma}_{\mathrm{m}}\right)=A_{\mathrm{g}} B_{\mathrm{g}} f_{\mathrm{cu}} \exp \left(\frac{\bar{\sigma}_{\mathrm{m}}-\frac{f_{\mathrm{tu}}}{3}}{B_{\mathrm{g}} f_{\mathrm{cu}}}\right),
$$

where $A_{\mathrm{g}}$ and $B_{\mathrm{g}}$ are model parameters (more information can be found in Ref. [29]) and $f_{\text {tu }}$ is the tensile strength of concrete. The hardening law is defined through the function $q_{\mathrm{h}}$ in Eq. (7). $q_{\mathrm{h}}$ is a function of the strain-like internal hardening variable $\alpha_{\mathrm{p}}$, and is defined as

$q_{\mathrm{h}}\left(\alpha_{\mathrm{p}}\right)= \begin{cases}\frac{f_{\mathrm{cy}}}{f_{\mathrm{cu}}}+\left(1-\frac{f_{\mathrm{cy}}}{f_{\mathrm{cu}}}\right) \alpha_{\mathrm{p}}\left(\alpha_{\mathrm{p}}^{2}-3 \alpha_{\mathrm{p}}+3\right), & \text { if } \alpha_{\mathrm{p}}<1, \\ 1, & \text { otherwise }\end{cases}$

where $f_{\text {cy }}$ is the uniaxial yield stress under compression. The direction of the plastic flow, $\mathbf{m}=\partial g_{\mathrm{p}} / \partial \overline{\boldsymbol{\sigma}}$, can be defined using the volumetric and deviatoric parts as

$$
\mathbf{m}=\frac{\partial g}{\partial \overline{\boldsymbol{\sigma}}}=\frac{\partial g}{\partial \bar{\sigma}_{\mathrm{m}}} \frac{\partial \bar{\sigma}_{\mathrm{m}}}{\partial \overline{\boldsymbol{\sigma}}}+\frac{\partial g}{\partial \bar{\rho}} \frac{\partial \bar{\rho}}{\partial \overline{\boldsymbol{\sigma}}} .
$$

In Eq. (10), the substitutions $\partial \bar{\sigma}_{\mathrm{m}} / \partial \overline{\boldsymbol{\sigma}}=\delta / 3$ and $\partial \bar{\rho} / \partial \overline{\boldsymbol{\sigma}}=\overline{\boldsymbol{s}} / \bar{\rho}$ can be made, where $\boldsymbol{\delta}$ is the Kronecker delta (i.e., identity) tensor and $\bar{s}$ is the deviatoric effective stress tensor. The other two terms $\partial g / \partial \bar{\sigma}_{\mathrm{m}}$ and $\partial g / \partial \bar{\rho}$ take the forms

$$
\begin{aligned}
\frac{\partial g}{\partial \bar{\sigma}_{\mathrm{m}}}= & 4\left(\left(\frac{1-q_{\mathrm{h}}}{f_{\mathrm{cu}}^{2}}\right)\left(\bar{\sigma}_{\mathrm{m}}+\frac{\bar{\rho}}{\sqrt{6}}\right)^{2}+\sqrt{1.5} \frac{\bar{\rho}}{f_{\mathrm{cu}}}\right) \\
& \times\left(\frac{1-q_{\mathrm{h}}}{f_{\mathrm{cu}}^{2}}\right)\left(\bar{\sigma}_{\mathrm{m}}+\frac{\bar{\rho}}{\sqrt{6}}\right)+\frac{q_{\mathrm{h}}^{2}}{f_{\mathrm{cu}}^{2}} \frac{m_{\mathrm{g}}}{B_{\mathrm{g}}},
\end{aligned}
$$

and

$$
\begin{aligned}
\frac{\partial g}{\partial \bar{\rho}}= & 2\left(\left(\frac{1-q_{\mathrm{h}}}{f_{\mathrm{cu}}^{2}}\right)\left(\bar{\sigma}_{\mathrm{m}}+\frac{\bar{\rho}}{\sqrt{6}}\right)^{2}+\sqrt{1.5} \frac{\bar{\rho}}{f_{\mathrm{cu}}}\right) \\
& \times\left(\frac{2}{\sqrt{6}}\left(\frac{1-q_{\mathrm{h}}}{f_{\mathrm{cu}}^{2}}\right)\left(\bar{\sigma}_{\mathrm{m}}+\frac{\bar{\rho}}{\sqrt{6}}\right)+\frac{\sqrt{1.5}}{f_{\mathrm{cu}}}\right) \\
& +\frac{q_{\mathrm{h}}^{2}}{f_{\mathrm{cu}}} \frac{m_{0}}{\sqrt{6}} .
\end{aligned}
$$

The evolution of the strain-like internal hardening variable, $\alpha_{\mathrm{p}}$, can be defined by employing the modified hardening law by Unteregger et al. [63]:

$$
\dot{\alpha}_{\mathrm{p}}=\frac{\left\|\dot{\boldsymbol{\varepsilon}}^{P}\right\|}{x_{\mathrm{h}}\left(\bar{\sigma}_{\mathrm{m}}\right)}\left(1+3 \frac{\bar{\rho}^{2}}{\bar{\rho}^{2}+10^{-8} f_{\mathrm{cu}}^{2}} \cos ^{2}\left(\frac{3 \theta}{2}\right)\right) .
$$

$x_{\mathrm{h}}\left(\bar{\sigma}_{\mathrm{m}}\right)$ denotes a hardening ductility measure and can be written as

$$
x_{\mathrm{h}}\left(\bar{\sigma}_{\mathrm{m}}\right)=\left\{\begin{array}{c}
A_{\mathrm{h}}-\left(A_{\mathrm{h}}-B_{\mathrm{h}}\right) \exp \left(\frac{-R_{\mathrm{h}}\left(\bar{\sigma}_{\mathrm{m}}\right)}{C_{\mathrm{h}}}\right), \\
\quad \text { if } R_{\mathrm{h}}\left(\bar{\sigma}_{\mathrm{m}}\right) \geqslant 0, \\
\left(B_{\mathrm{h}}-D_{\mathrm{h}}\right) \exp \left(\frac{R_{\mathrm{h}}\left(\bar{\sigma}_{\mathrm{m}}\right)\left(A_{\mathrm{h}}-B_{\mathrm{h}}\right)}{\left(B_{\mathrm{h}}-D_{\mathrm{h}}\right) C_{\mathrm{h}}}\right)+D_{\mathrm{h}}, \\
\text { otherwise, }
\end{array}\right.
$$

where $A_{\mathrm{h}}, B_{\mathrm{h}}, C_{\mathrm{h}}$, and $D_{\mathrm{h}}$ are model parameters that can be calibrated from the experimentally measured values of the strain at the ultimate tensile stress. The variable $R_{\mathrm{h}}\left(\bar{\sigma}_{\mathrm{m}}\right)$ takes the form

$$
R_{\mathrm{h}}\left(\bar{\sigma}_{\mathrm{m}}\right)=-\frac{\bar{\sigma}_{\mathrm{m}}}{f_{\mathrm{cu}}}-\frac{1}{3} .
$$

The isotropic damage variables, which represent the softening behavior of concrete, can be defined in the compressive and tensile regimes as

$$
D_{\mathrm{c}}=1-e^{-\frac{a_{\mathrm{dc}}}{\epsilon_{\mathrm{fc}}}},
$$




$$
D_{\mathrm{t}}=1-e^{-\frac{a_{\mathrm{dt}}}{\epsilon_{\mathrm{ft}}}},
$$

respectively. It is worth noting that Eqs. (16) and (17) are defined by splitting the damage parameter proposed in Ref. [29] into two damage variables for the tensile and compressive regimes. According to Grassl et al. [61], the softening modulus under compression is given by

$$
\epsilon_{\mathrm{fc}}=\frac{G_{\mathrm{FC}}}{f_{\mathrm{cu}} l_{\mathrm{char}} A_{\mathrm{s}}},
$$

wherein the compressive fracture energy can be defined as [64]

$$
G_{\mathrm{FC}}=\left(\frac{f_{\mathrm{cu}}}{f_{\mathrm{tu}}}\right)^{2} G_{\mathrm{FI}} .
$$

The softening modulus under tension $\epsilon_{\mathrm{ft}}$ can be computed using the specific mode-I fracture energy $G_{\mathrm{FI}}$, the characteristic size of a finite element $l_{\text {char }}$, and the Young's modulus $E$ as [65]

$$
\epsilon_{\mathrm{ft}}=\frac{G_{\mathrm{FI}}}{f_{\mathrm{tu}} l_{\mathrm{char}}}-\frac{f_{\mathrm{tu}}}{2 E} .
$$

The evolution of the damage driving the internal variables under compression $\alpha_{\mathrm{dc}}$ and tension $\alpha_{\mathrm{dt}}$ is given by

$$
\begin{aligned}
& \dot{\alpha}_{\mathrm{dc}}= \begin{cases}\frac{\alpha_{\mathrm{c}} \dot{\varepsilon}_{\mathrm{V}}^{\mathrm{P}}}{x_{\mathrm{s}}\left(\bar{\sigma}_{\mathrm{m}}\right)}, & \text { if } \alpha_{\mathrm{p}}>1 \text { and } \dot{\varepsilon}_{\mathrm{V}}^{\mathrm{P}}>0, \\
0, & \text { otherwise, }\end{cases} \\
& \dot{\alpha}_{\mathrm{dt}}= \begin{cases}\frac{\left(1-\alpha_{\mathrm{c}}\right) \dot{\varepsilon}_{\mathrm{V}}^{\mathrm{P}}}{x_{\mathrm{s}}\left(\bar{\sigma}_{\mathrm{m}}\right)}, & \text { if } \alpha_{\mathrm{p}}>1 \text { and } \dot{\varepsilon}_{\mathrm{V}}^{\mathrm{P}}>0, \\
0, & \text { otherwise, }\end{cases}
\end{aligned}
$$

respectively. $\alpha_{\mathrm{c}}$ is a variable ranging from 0 (uniaxial tension) to 1 (uniaxial compression) that distinguishes between tensile and compressive loading and is given by [61]

$$
\alpha_{\mathrm{c}}=\sum_{I=1}^{3} \frac{\bar{\sigma}_{\mathrm{PCI}}\left(\bar{\sigma}_{\mathrm{PTI}}+\bar{\sigma}_{\mathrm{PCI}}\right)}{\left\|\overline{\boldsymbol{\sigma}}_{\mathrm{P}}\right\|^{2}}
$$

where $\bar{\sigma}_{\mathrm{PCI}}$ and $\bar{\sigma}_{\mathrm{PTI}}$ denote the components of the compressive and tensile part of the principal effective stresses, respectively, and $x_{\mathrm{s}}\left(\bar{\sigma}_{\mathrm{m}}\right)$ denotes a softening ductility measure

$$
x_{\mathrm{s}}\left(\bar{\sigma}_{\mathrm{m}}\right)=1+\left(A_{\mathrm{s}}-1\right) R_{\mathrm{s}} .
$$

The model parameter $A_{\mathrm{s}}$ can be calibrated from the softening response in uniaxial compression tests, and the function $R_{\mathrm{s}}\left(\bar{\sigma}_{\mathrm{m}}\right)$ is defined as

$$
R_{\mathrm{s}}\left(\bar{\sigma}_{\mathrm{m}}\right)= \begin{cases}\frac{-\sqrt{6} \bar{\sigma}_{\mathrm{m}}}{\bar{\rho}}, & \text { if } \bar{\sigma}_{\mathrm{m}} \leqslant 0 \\ 0, & \text { otherwise }\end{cases}
$$

\section{Validation of ECDPM}

The numerical results predicted by ECDPM are compared with the measurements from laboratory experiments in this section. Several monotonic and cyclic tests, including a uniaxial tension test, and uniaxial, biaxial, and triaxial compression tests, were performed. The results are discussed in the following subsections.

\subsection{Uniaxial cyclic tension and compression tests}

The uniaxial tensile test performed by Gopalaratnam and Shah [66] focused on the softening response of plain concrete under cyclic loading. The concrete in this test is characterized by the following material parameters: Young's modulus $E=28 \mathrm{GPa}$, Poisson's ratio $v=0.20$, uniaxial compressive strength $f_{\text {cu }}=40 \mathrm{MPa}$, uniaxial tensile strength $f_{\mathrm{tu}}=3.5 \mathrm{MPa}$, and specific mode-I fracture energy $G_{\mathrm{FI}}=0.055 \mathrm{~N} / \mathrm{mm}$. The model parameter $A_{\mathrm{S}}$ was identified as $A_{\mathrm{s}}=15$. Wedge-type frictional grips were employed in this test as shown in Fig. 3(a). The comparisons are presented in Fig. 3(b), from which it can be observed that there is very good agreement between the ECDPM predictions and the experimental data.

Next, the performance of ECDPM in modeling the cyclic behavior of plain concrete under uniaxial compression is evaluated. For this, the ECDPM predictions are compared against data from two experiments performed by Karsan and Jirsa [67] and Van Mier [68].

Karsan and Jirsa's experiment is a uniaxial compression test for which the material parameters are $E=30 \mathrm{GPa}, v=$ $0.20, f_{\mathrm{cu}}=28 \mathrm{MPa}$, and $f_{\mathrm{tu}}=2.8 \mathrm{MPa}$, and the model parameter was identified as $A_{\mathrm{s}}=5$. The specific Mode-I fracture energy $G_{\mathrm{FI}}$ was estimated using the FIB (International Federation for Structural Concrete) model code for concrete structures [69], and the Poisson's ratio $v$ and the uniaxial compression yield stress $f_{\text {cy }}$ were assumed based on similar grades of concrete. The model predictions and experimental data are shown in Fig. 4, from which it can be seen that ECDPM predicts the ultimate compressive strength and softening responses very well.

The material parameters for the uniaxial compression test performed by Van Mier [68] are $E=33 \mathrm{GPa}, v=0.20$, $f_{\mathrm{cu}}=42.3 \mathrm{MPa}, f_{\mathrm{tu}}=2.8 \mathrm{MPa}$, and $G_{\mathrm{FI}}=0.15 \mathrm{~N} / \mathrm{mm}$, and the model parameter was identified as $A_{\mathrm{s}}=10$. It is noted here that the Young's modulus $E$ was computed from the experimental data [68]. The details of the single loading frame employed by Van Mier [68] are shown in Fig. 5(a). The predicted and observed results for the tested specimen are shown in Fig. 5(b). It can be seen in the left half of Fig. 5(b) that the softening response of the plain concrete specimen along the loading direction is captured very well by ECDPM. On the other hand, it can be seen in the right half of Fig. 5(b) that ECDPM considerably underestimates 


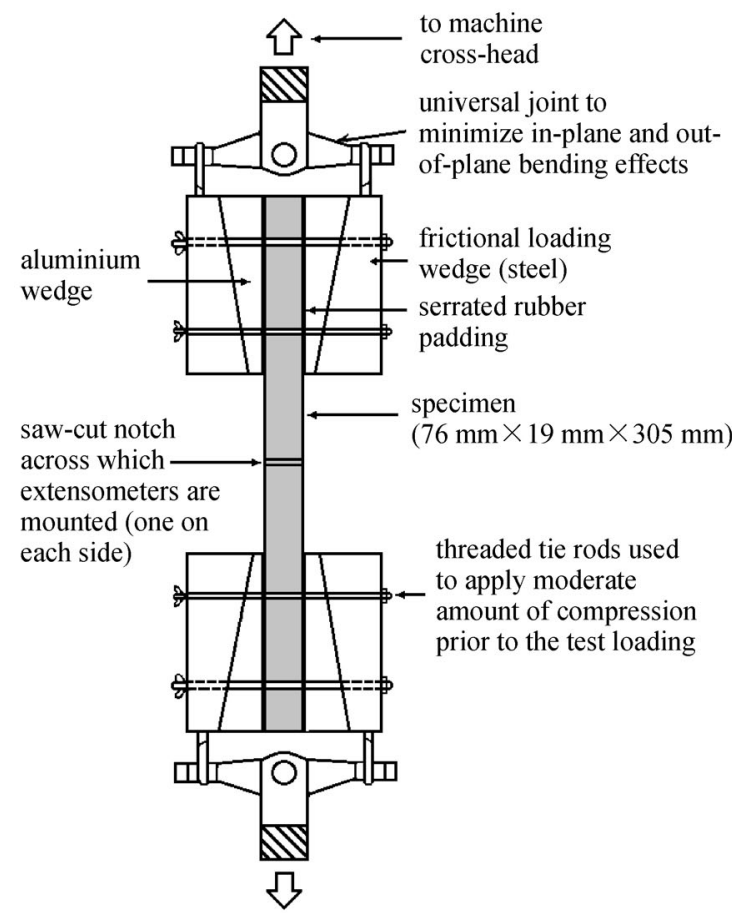

(a)

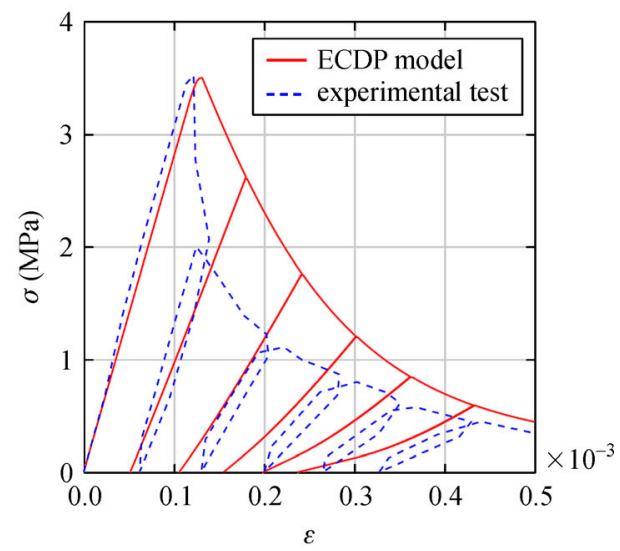

(b)

Fig. 3 (a) Scheme of wedge-type frictional grips adopted from Ref. [66]; (b) comparison of predicted and observed concrete responses in a uniaxial cyclic tension test by Gopalaratnam and Shah [66].

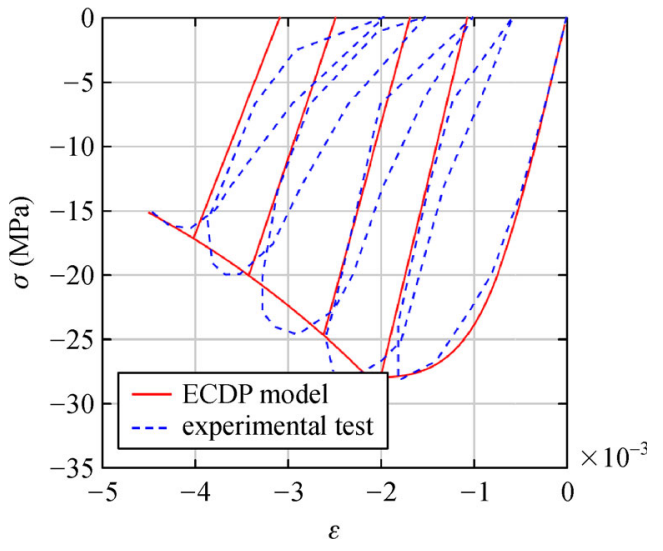

Fig. 4 Comparison of predicted and observed concrete behavior in the uniaxial cyclic compression test by Karsan and Jirsa [67].

the lateral strains measured at the free surfaces. Van Mier [68] stated that the measurements of the lateral strains were probably disturbed by the splitting phenomena. As such, it is not clear whether the discrepancy observed between ECDPM and Van Mier's reported lateral strains is indicative of a problem with ECDPM, or due to an artifact of the specimen-sensor configuration.

It should be noted that the stress-strain diagrams in the softening region in Figs. 2, 4, and 5 were computed using the characteristic length $l_{\text {char }}$ of $100 \mathrm{~mm}$.

\subsection{Biaxial cyclic compression tests}

Data from two biaxial (monotonic and cyclic loading) experiments performed by Kupfer et al. [70] and Van Mier [68] were also employed to evaluate ECDPM.

The first of these data sets is from the uniaxial and biaxial monotonic tests by Kupfer et al. [70]. The material parameters for concrete in these tests are $E=32 \mathrm{GPa}, v=$ $0.18, f_{\mathrm{cu}}=32.8 \mathrm{MPa}$, and $f_{\mathrm{tu}}=3.3 \mathrm{MPa}$, and the Mode-I fracture energy $G_{\mathrm{FI}}$ was estimated as $0.145 \mathrm{~N} / \mathrm{mm}$ [69]. The model constant $A_{\mathrm{s}}$ was reported as 1.5 in Ref. [61]. Lateral confining pressures $\left(\sigma_{2}\right)$ of $50 \%$ and $100 \%$ of the uniaxial compressive strength were applied to the specimens. Figure 6 displays the responses predicted by ECDPM and the measurements from the tests. As can be seen, ECDPM captures the concrete behavior in these uniaxial and biaxial tests very well.

In the biaxial cyclic loading tests by Van Mier [68], the model parameters are $E=25 \mathrm{GPa}, v=0.20, f_{\mathrm{cu}}=47.9$ $\mathrm{MPa}, f_{\mathrm{tu}}=3.1 \mathrm{MPa}$, and $G_{\mathrm{FI}}=0.15 \mathrm{~N} / \mathrm{mm}$, and the model constant was identified as $A_{\mathrm{s}}=7.5$. The lateral confining stress $\left(\sigma_{2}\right)$ was considered to be $5 \%$ of the uniaxial compressive strength and $\sigma_{3}=0$ [68]. Figure 7 displays the predicted and measured responses. It can be seen in Fig. 7(a) that the ECDP model predicts the stress-strain response $\left(\sigma_{1}-\varepsilon_{1}\right)$ of the tested specimen very well, especially the influence of the lateral confining pressure on both the strength and ductility, as well as the softening 


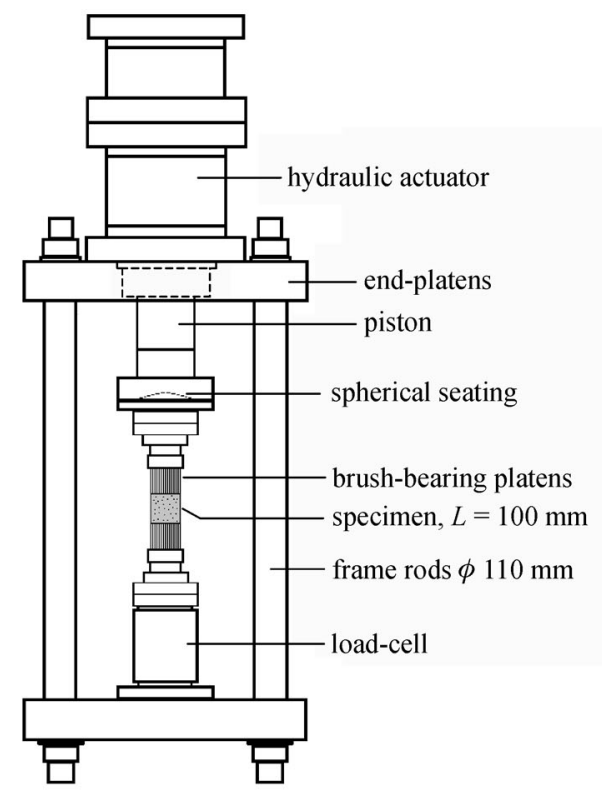

(a)

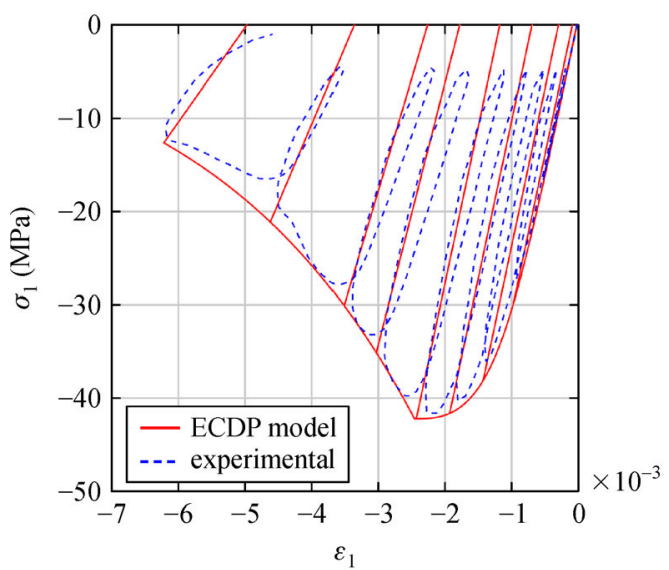

(b)

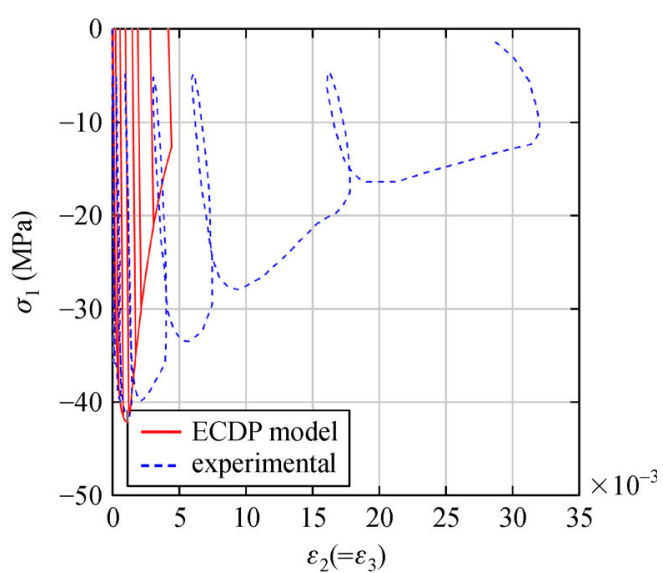

(c)

Fig. 5 (a) Schematic of a single loading frame adopted from Ref. [68]. Comparison of predicted and observed concrete behavior in a uniaxial cyclic compression test reported by Van Mier [68]: (b) $\sigma_{1}-\varepsilon_{1} ;$ (c) $\sigma_{1}-\varepsilon_{2}$.

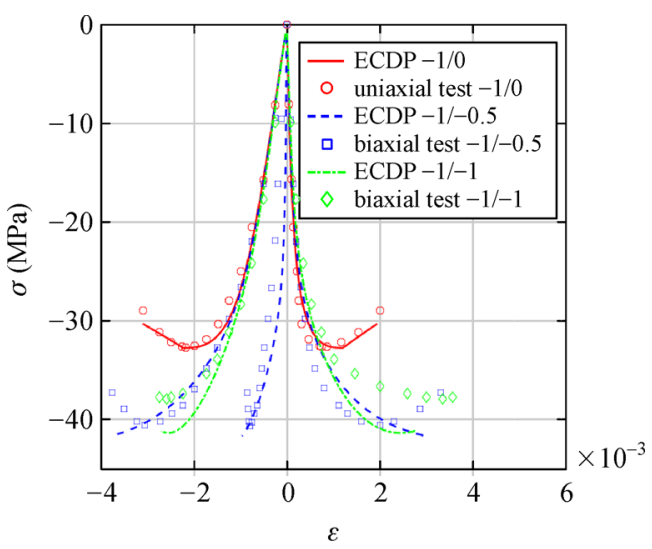

Fig. 6 Comparison of predicted and observed concrete behavior in biaxial compression tests conducted by Kupfer et al. [70]. response in the post-peak region. Again, the issue discussed in the preceding section regarding lateral strains at the free-surface of the specimen is observed in this test as well in Fig. 7(b).

The characteristic length for computing the softening region of the stress-strain diagrams employed is $100 \mathrm{~mm}$ for all the biaxial compression tests, which follows from the specimen dimensions provided in the test reports.

\subsection{Triaxial cyclic compression tests}

Data from tests on confined concrete specimens subjected to triaxial monotonic and cyclic loads by Imran and Pantazopoulou [71] and Van Mier [68] were also considered.

The first of these data sets is from the tests carried out by 


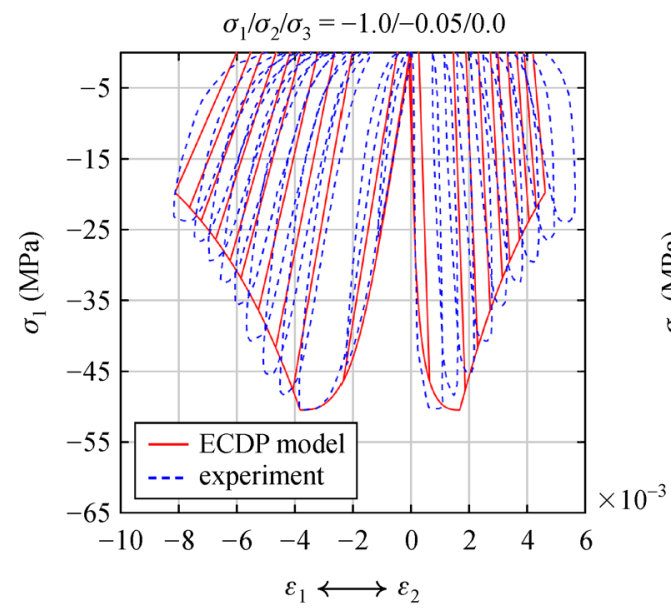

(a)

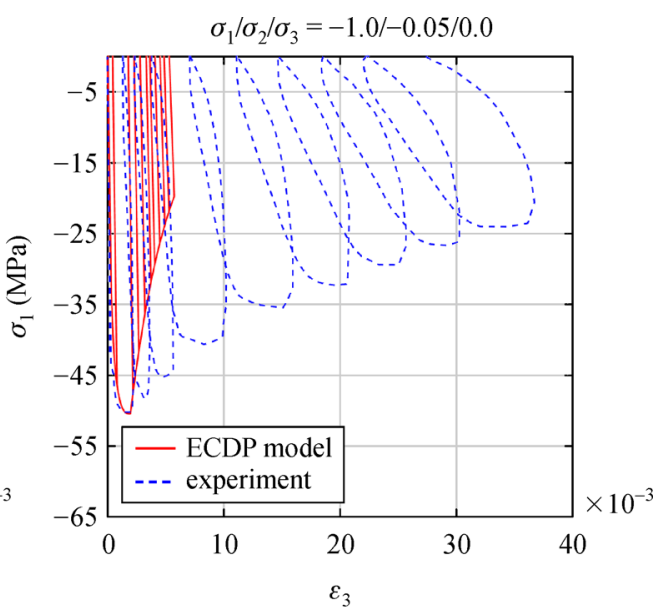

(b)

Fig. 7 Comparison of predicted and observed concrete behavior in biaxial cyclic compression tests conducted by Van Mier [68]. (a) Stress along the loading direction $\left(\sigma_{1}\right)$ versus the strain along the loading direction $\left(\varepsilon_{1}\right)$ and the strain along the lateral pressure directions $\left(\varepsilon_{2}\right)$; (b) stress along the loading direction $\left(\sigma_{1}\right)$ versus the strain at the free surface $\left(\varepsilon_{3}\right)$.

Imran and Pantazopoulou [71], who examined the influence of different levels of lateral confinement (ranging from 0 to $-43 \mathrm{MPa}$ ) on the strength and ductility of plain concrete under monotonic loading. The reported concrete mechanical properties are $E=30 \mathrm{GPa}, v=0.20, f_{\mathrm{cu}}=47.4$ $\mathrm{MPa}$, and $f_{\mathrm{tu}}=4.74 \mathrm{MPa}$. The specific Mode-I fracture energy $G_{\mathrm{FI}}$ was computed as $0.15 \mathrm{~N} / \mathrm{mm}$ [69] and the model constant $A_{\mathrm{s}}$ was taken as 15 , as reported in Ref. [61]. Figure 8 illustrates the experimental setup of the confined compression tests, which was adopted from Ref. [71]. The computed ECDPM results are shown along with the test data in Fig. 8, wherein very good agreement is observed at all levels of lateral confinement pressure.

The performance of ECDPM in capturing the cyclic response of plain concrete under triaxial loading conditions

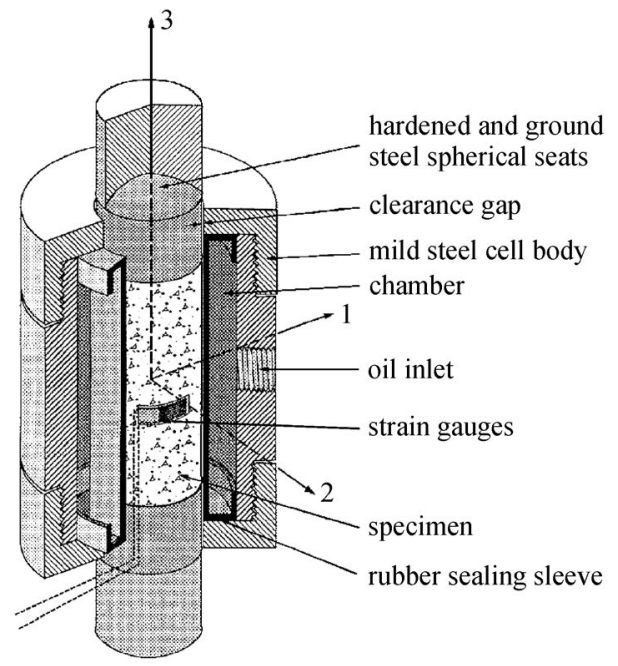

(a) is evaluated by considering two triaxial cyclic tests conducted by Van Mier [68]. In the first test, the reported concrete material parameters are $E=35 \mathrm{GPa}, v=0.20$, $f_{\mathrm{cu}}=47.9 \mathrm{MPa}, f_{\mathrm{tu}}=3.1 \mathrm{MPa}$, and $G_{\mathrm{FI}}=0.15 \mathrm{~N} / \mathrm{mm}$, and the model constant was identified as $A_{\mathrm{s}}=2.5$. In this test, lateral confining pressures $\sigma_{2}$ and $\sigma_{3}$ of $10 \%$ and $5 \%$ of the uniaxial compressive strength were respectively applied to the specimen [68]. The predicted results from ECDPM are illustrated in Fig. 9. It can be seen in Fig. 9 that the concrete response is well predicted by ECDPM along the loading direction $\left(\sigma_{1}-\varepsilon_{1}\right)$. Nevertheless, ECDPM overestimates the lateral strain $\left(\varepsilon_{2}\right)$ in the direction with higher lateral pressure and considerably underestimates the lateral strain $\left(\varepsilon_{3}\right)$ in the direction with lower lateral pressure.

Next, the ECDP model is also examined with data from

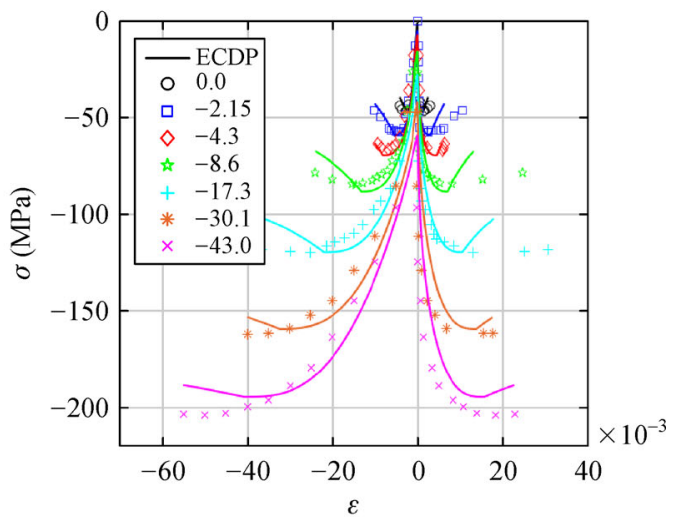

(b)

Fig. 8 (a) Experimental setup of the triaxial tests reprinted from Ref. [71] (Courtesy of the American Concrete Institute, Farmington Hills, MI.); (b) comparison of predicted and observed behavior of confined concrete at different levels of confinement ranging from 0 to $43 \mathrm{MPa}$ in tests conducted by Imran and Pantazopoulou [71]. 
another triaxial cyclic test performed by Van Mier [68]. In this test, the model parameters are $E=27 \mathrm{GPa}, v=0.20$, $f_{\mathrm{cu}}=45.3 \mathrm{MPa}, f_{\mathrm{tu}}=2.8 \mathrm{MPa}$, and $G_{\mathrm{FI}}=0.15 \mathrm{~N} / \mathrm{mm}$, and the model constant was identified as $A_{\mathrm{s}}=1.5$. In this test, equal lateral confining stresses $\sigma_{2}=\sigma_{3}$ were applied to the specimen at $10 \%$ of the uniaxial compressive strength [68]. The responses predicted by ECDPM are shown together with the measurements in Fig. 10 and very good agreement is observed. It is useful to note here that all of the three strains are well reproduced by ECDPM for this triaxial test wherein there were no free surfaces or surfaces with low levels of lateral pressure, unlike the case for Van Mier's uniaxial, biaxial, and triaxial tests which were examined above.

The softening response in Figs. 8, 9, and 10 was computed by employing the characteristic length of 100 $\mathrm{mm}$ based on the specimen dimensions provided in the test reports.

\subsection{Uniaxial cyclic tension-compression test}

Herein, the ECDP model is assessed with data from a cyclic uniaxial test with alternating tension-compression by Reinhardt et al. [72], and it is also compared to other damage plasticity models for concrete, namely CDPM by Lee and Fenves [60], CDPM1 by Grassl and Jirásek [29], and CDPM2 by Grassl et al. [61]. It is important to note that the uniaxial cyclic test by Reinhardt et al. [72] is, to the best of the authors' knowledge, the only experimental data set with alternating tension-compression available in the open literature that can be used to examine the effects of compressive damage on the tensile behavior of plain concrete and vice versa.

In this experiment, the concrete attained its ultimate tensile strength while its behavior under compression was probed within the elastic regime. It is also useful to note that both CDPM and CDPM2 have been previously examined and have demonstrated their capabilities in capturing the tensile response of plain concrete well (the same/similar demonstrations are omitted here for brevity). However, unlike ECDPM, neither CDPM nor CDPM2 has been devised to capture the influence of tensile damage on the (effective) compressive stiffness. As such, the

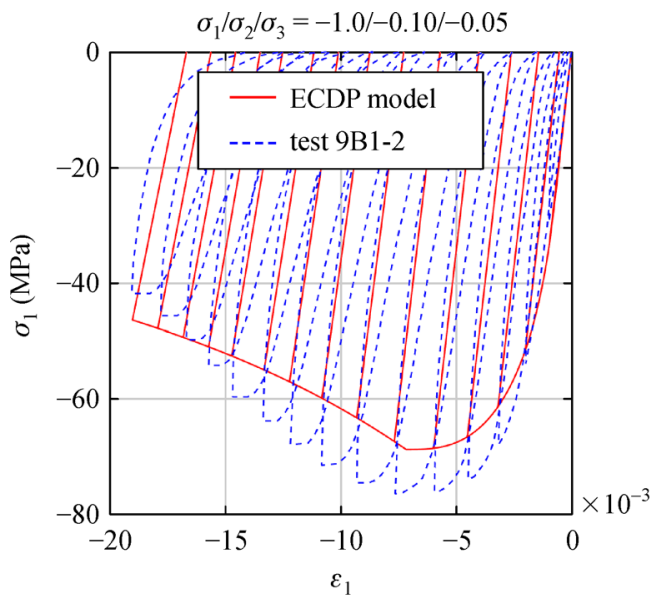

(a)

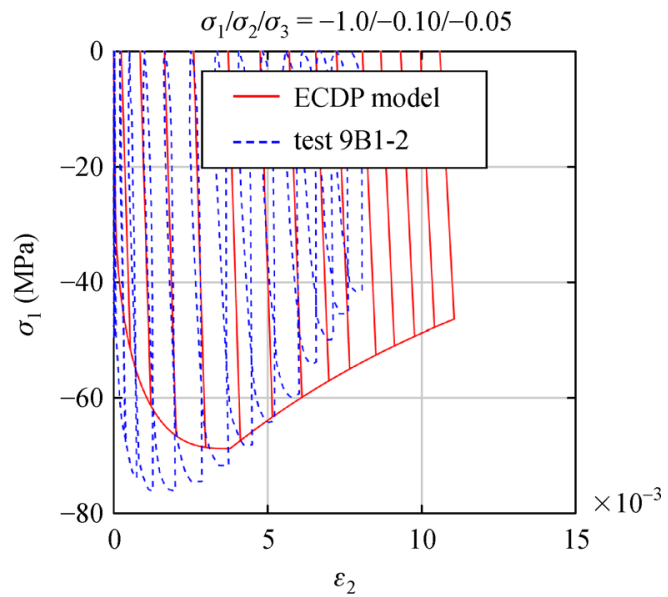

(b)

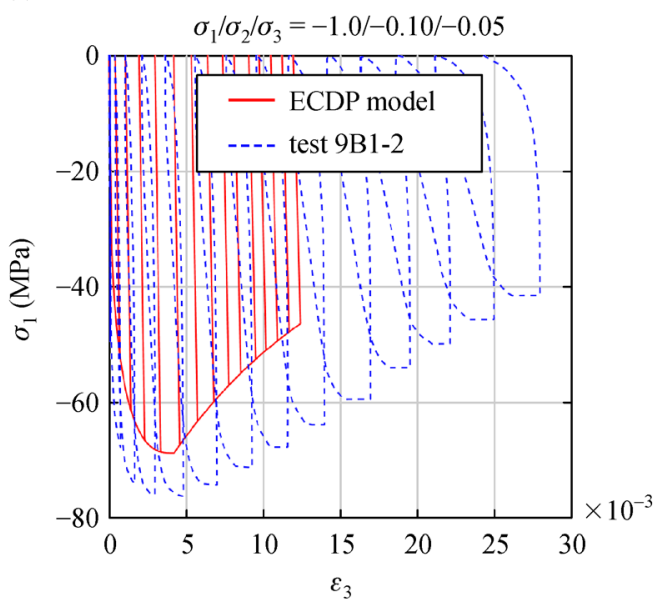

(c)

Fig. 9 Comparison of predicted and observed concrete behavior in triaxial cyclic compression test carried out by Van Mier [68]. (a) $\sigma_{1}-\varepsilon_{1} ;$ (b) $\sigma_{1}-\varepsilon_{2} ;$ (c) $\sigma_{1}-\varepsilon_{3}$. 


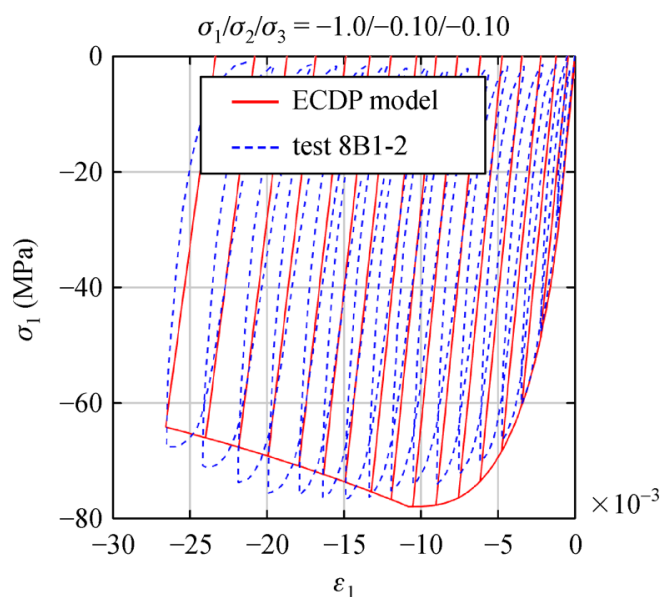

(a)

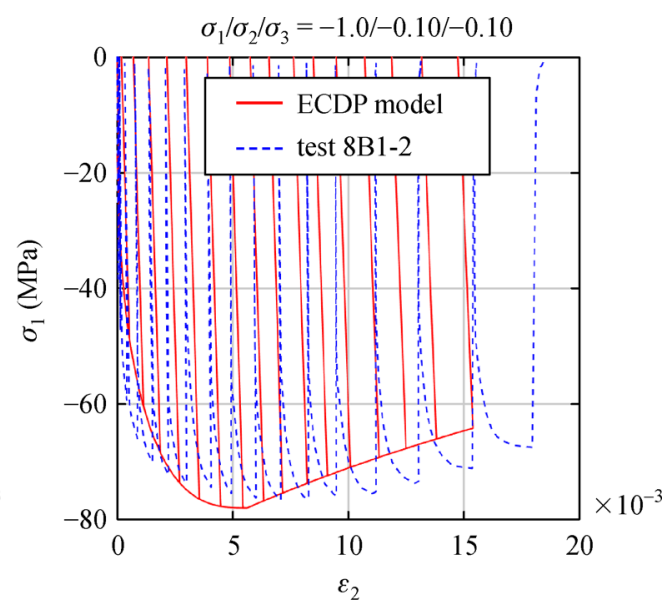

(b)

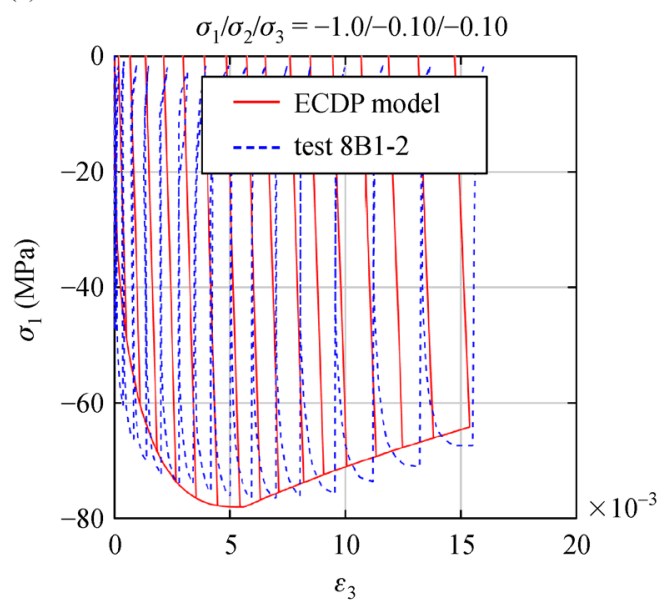

(c)

Fig. 10 Comparison of predicted and observed concrete behavior in triaxial cyclic compression test carried out by Van Mier [68]. (a) $\sigma_{1}-\varepsilon_{1} ;$ (b) $\sigma_{1}-\varepsilon_{2} ;$ (c) $\sigma_{1}-\varepsilon_{3}$.

measurements from the test by Reinhardt et al. [72] form an especially important and unique data set for model validation.

The material parameters for concrete are $E=24 \mathrm{GPa}$, $f_{\mathrm{cu}}=47.1 \mathrm{MPa}, f_{\mathrm{tu}}=3.20 \mathrm{MPa}$, and $G_{\mathrm{FI}}=0.06 \mathrm{~N} / \mathrm{mm}$. The Poisson's ratio was assumed to be $v=0.20$, and $l_{\text {char }}$ was taken as $35 \mathrm{~mm}$. The responses predicted by ECDPM and the other two damage plasticity models are presented along with the test data in Fig. 11.

The test data are compared to the predictions from CDPM2 and CDPM in Figs. 11(b) and 11(c), respectively, from which it can be seen that neither of the models can capture the transitions from tension to compression and vice vera observed in the test. The compressive stiffnesses from both models are equal to the intact/initial elastic modulus, and do not evolve with the cyclic transitions between the tensile and compressive loading regimes. In short, it can be concluded that tensile damage does not influence the compressive stiffness in these models, which is expected from their formulation. It can also be seen in Figs. 11(b) and 11(c) that the residual tensile strains are inaccurately predicted by both CDPM and CDPM2 when $\sigma$ $=-3.4 \mathrm{MPa}$. In contrast, ECDPM predicts the near-lack of residual tensile strains at $\sigma=-3.4 \mathrm{MPa}$ very well because the compressive stiffness is reduced by tensile damage, as shown in Fig. 11(a). It is worth noting that the numerical test on CDPM [60] here was performed using the preexisting implementation in the finite element software package ABAQUS [73].

In Fig. 11(d), the predicted cyclic response of another concrete damage plasticity model dubbed CDPM1 by Grassl and Jirásek [29] is also compared to the test data. Unlike ECDPM, CDPM, and CDPM2, this model (CDPM1) features a single damage variable and for the comparison at hand, appears to produce a reasonable prediction which is nearly identical to that of the ECDP model. Moreover, the capabilities of CDPM1 in capturing the responses of plain concrete and reinforced concrete structures under monotonic loading scenarios have been demonstrated in prior studies [74,75]. However, it is still unclear whether the single-damage formulation of CDPM1 is capable of capturing the cyclic behavior under the full 


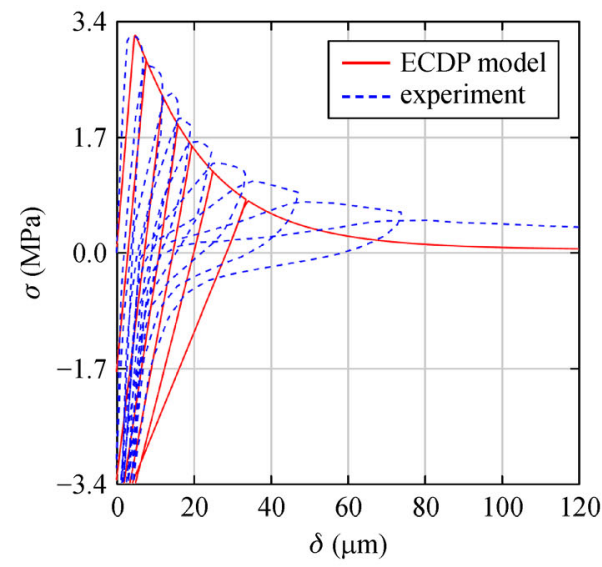

(a)

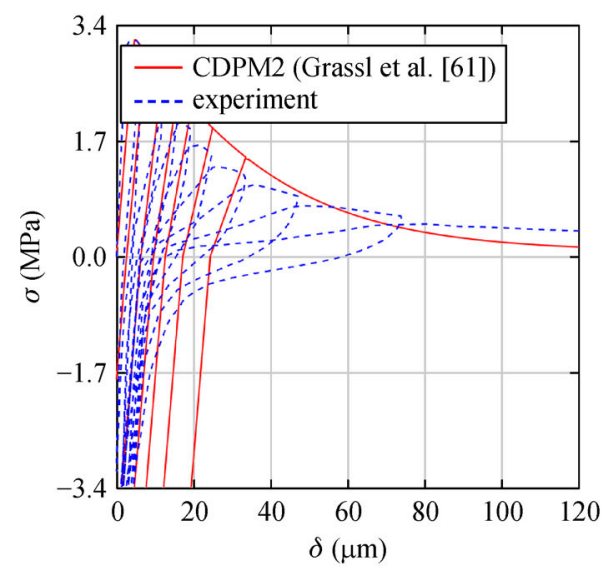

(c)

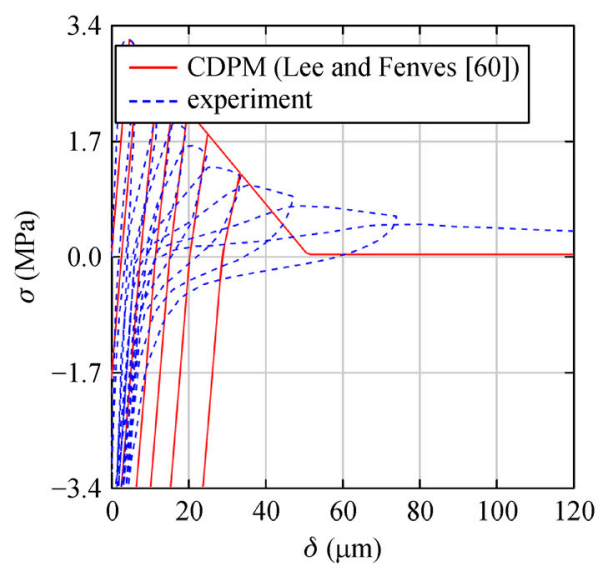

(b)

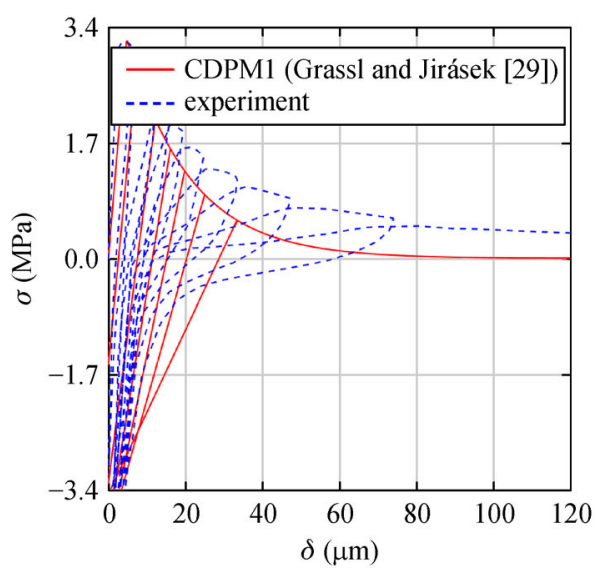

(d)

Fig. 11 Comparison of predicted and observed concrete behavior in uniaxial cyclic test performed by Reinhardt et al. [72]. (a) Experiment vs. the predictions by ECDP model; (b) experiment vs. the predictions by CDPM [60]; (c) experiments vs. the predictions by CDPM2 [61]; (d) experiments vs. the predictions by CDPM1 [29].

range of compressive stresses, especially up to the compressive strength, and then within the post-compressive failure regimes.

To clarify the potential shortcomings of CDPM1 (and incidentally, those of CDPM and CDPM2), the cyclic behavior envelope curves of plain concrete in a straindriven virtual test $\left(\varepsilon=0,0.25 \times 10^{-3},-2 \times 10^{-3}\right.$, unloading) predicted by CDPM [60], CDPM1 [29], CDPM2 [61], and ECDPM are shown in Fig. 12. The material and model parameters were set as $E=15 \mathrm{GPa}, v=0.20, f_{\mathrm{cu}}=10 \mathrm{MPa}$, $f_{\mathrm{tu}}=1 \mathrm{MPa}, G_{\mathrm{FI}}=0.02 \mathrm{~N} / \mathrm{mm}, A_{\mathrm{s}}=15$, and $l_{\text {char }}=100 \mathrm{~mm}$. The predicted concrete responses in the tensile regime by all the models are almost identical. In all the models, the concrete reaches its designated ultimate tensile strength, and the capacity continues to decrease in the post-peak region due to accumulated tensile damage. Nevertheless, the models predict different compressive responses. To wit, for CDPM1 (denoted by the magenta-colored dashed line) [29], the initial compressive stiffness of the concrete is equal to the reduced tensile stiffness when the loading branch changes and the stress enters into the compressive regime because of the employment of only a single damage variable. This results in a significant loss of compressive strength $\left(\sigma_{\mathrm{C}} \approx-2 \mathrm{MPa}\right)$. Because only a single damage variable is employed in CDPM1, it is not possible to control both the deterioration in stiffness and that in compressive strength independently with the model. In contrast, ECDPM allows such control (denoted by the red dashed line) and the reduction of the ultimate compressive strength (here to $\sigma_{\mathrm{C}} \approx-7 \mathrm{MPa}$ ) due to tensile damage, for which the reduction is not purely dictated by the loss of stiffness, unlike in CDPM1. This feature of ECDPM enables the implicit consideration of the closure of tension cracks and the subsequent recovery of compressive stiffness (see the inflection point in the ECDPM curve at $\sigma \approx-1 \mathrm{MPa}$ in Fig. 12) in a phenomenological manner as opposed to, for example, a micro-mechanics manner wherein cracks are individually modeled and tracked.

As for CDPM (denoted by the blue dashed line) [60] and CDPM2 (denoted by the black dashed line) [61], the concrete reaches its monotonic ultimate compressive strength regardless of the tensile damage it has already 


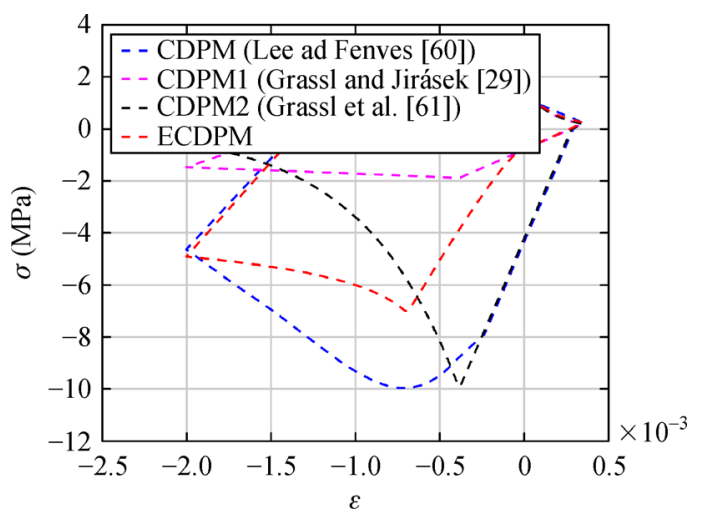

Fig. 12 Comparison of the cyclic response of CDPM [60], CDPM1 [29], CDPM2 [61], and ECDPM.

suffered in the predictions by these models because the models employ uncoupled damage variables for tension and for compression, and the initial compressive stiffnesses are not affected by the tensile damage and remain intact.

Test data on plain concrete wherein the sample is cycled through tensile and compressive strains such as those applied in the virtual test shown in Fig. 12 do not currently exist in the open literature. As such, in order to fully examine and validate ECDPM and to compare it with CDPM1, one has to either carry out such cyclic tests on plain concrete specimens, or rely on structural componentlevel tests (e.g., on reinforced concrete shear walls, beams, and beam-column joints) for which data are available in extensive databases $[76,77]$.

\section{Summary and conclusions}

An ECDPM was proposed for simulating the cyclic behavior of plain concrete under multiaxial loading conditions. This model combines the theories of plasticity and continuum damage mechanics like many of its predecessors; however, it crucially features two damage parameters and a strain-based split weight factor to capture the influence of tensile damage on the compressive response and vice-versa. The performance of ECDPM was evaluated using data sets from a number of experiments including a uniaxial tension test and uniaxial, biaxial, and triaxial compression tests under monotonic and cyclic loading conditions.

The results indicate that ECDPM uniformly exhibits high accuracy and fidelity against the test data with a single exception for lateral strains under low confinement pressures (which is estimated here as not being problematic for common earthquake engineering applications), and is generally superior to the prior CDPM [60], CDPM1 [29], and CDPM2 [61] continuum damage plasticity models. Specifically, ECDPM appears to accurately predict the cyclic behavior of plain concrete, the impacts of lateral confinement on strength and ductility, as well as the tensile and compressive softening responses in the post-peak regions. Future studies are needed to further examine the relative accuracies of these models, especially in predicting system/component-level behavior, for which ECDPM appears to hold better promise. The current lack of experimental data from plain concrete specimens under cyclic tension-compression strain cycles presents a lack of opportunities for model validation and is a major challenge for the development of more accurate and sophisticated continuum-based constitutive models than ECDPM. Despite the high accuracy of ECDPM at the material level, its performance can be further examined at the structural level by simulating the cyclic behavior of RC structures subjected to a combination of axial loads and reversed cyclic loading. This can be considered as a future work which can provide detailed information on the cyclic response of RC structures, such as the damage evolution in concrete and stress distribution in the reinforcement, during earthquakes and provide better perspectives on the seismic design of RC structures.

\footnotetext{
Acknowledgements The authors acknowledge the financial support of this study by the Austrian Marshall Plan Foundation, which funded the first author's short-term visit to UCLA during the course of this study. The authors would also like to acknowledge the guidance and support provided by Prof. Günter Hofstetter in developing this manuscript.
}

Open Access This article is licensed under a Creative Commons Attribution 4.0 International License, which permits use, sharing, adaptation, distribution and reproduction in any medium or format, as long as you give appropriate credit to the original author(s) and the source, provide a link to the Creative Commons licence, and indicate if changes were made.

The images or other third party material in this article are included in the article's Creative Commons licence, unless indicated otherwise in a credit line to the material. If material is not included in the article's Creative Commons licence and your intended use is not permitted by statutory regulation or exceeds the permitted use, you will need to obtain permission directly from the copyright holder.

To view a copy of this licence, visit http://creativecommons.org/licenses/ by $/ 4.0 /$.

\section{References}

1. Ellingwood B R. Earthquake risk assessment of building structures. Reliability Engineering \& System Safety, 2001, 74(3): 251-262

2. Sezen H. Seismic response and modeling of reinforced concrete building columns. Dissertation for the Doctoral Degree. Berkeley: University of California, Berkeley, 2002

3. Elwood K J. Shake table tests and analytical studies on the gravity load collapse of reinforced concrete frames. Dissertation for the Doctoral Degree. Berkeley: University of California, Berkeley, 2004

4. Zhu L, Elwood K J, Haukaas T. Classification and seismic safety evaluation of existing reinforced concrete columns. Journal of Structural Engineering, 2007, 133(9): 1316-1330

5. Haselton C B, Goulet C A, Mitrani-Reiser J, Beck J L, Deierlein G G, Porter K A, Stewart J P, Taciroglu E. An Assessment to 
Benchmark the Seismic Performance of a Code-Conforming Reinforced-Concrete Moment-Frame Building. Berkeley, CA: Pacific Earthquake Engineering Research Center, 2008

6. Yavari S. Shaking table tests on the response of reinforced concrete frames with non-seismic detailing. Dissertation for the Doctoral Degree. Vancouver: University of British Columbia, 2011

7. Elmer V, Taciroglu E, McMichael L. Dynamic strength increase of plain concrete from high strain rate plasticity with shear dilation. International Journal of Impact Engineering, 2012, 45: 1-15

8. Adibi M, Marefat M S, Allahvirdizadeh R. Nonlinear modeling of cyclic response of RC beam-column joints reinforced by plain bars. Bulletin of Earthquake Engineering, 2018, 16(11): 5529-5556

9. Azadi Kakavand M R, Allahvirdizadeh R. Enhanced empirical models for predicting the drift capacity of less ductile RC columns with flexural, shear or axial failure modes. Frontiers of Structural and Civil Engineering, 2019, 13(5): 1251-1270

10. Farahmand H, Azadi Kakavand M R, Tavousi Tafreshi S, Hafiz P. The effect of mechanical and geometric parameters on the shear and axial failures of columns in reinforced concrete frames. Ciência e Natura, 2015, 37(6-1): 247-259

11. Azadi Kakavand M R. Limit State Material Manual. Berkeley: University of California, Berkeley, 2012

12. Allahvirdizadeh R, Khanmohammadi M, Marefat M S. Probabilistic comparative investigation on introduced performance-based seismic design and assessment criteria. Engineering Structures, 2017, 151: 206-220

13. Allahvirdizadeh R, Gholipour Y. Reliability evaluation of predicted structural performances using nonlinear static analysis. Bulletin of Earthquake Engineering, 2017, 15(5): 2129-2148

14. Kent D C, Park R. Flexural members with confined concrete. Journal of the Structural Division, 1971, 97(7): 1969-1990

15. Popovics S. A numerical approach to the complete stress-strain curve of concrete. Cement and Concrete Research, 1973, 3(5): 583599

16. Mander J B, Priestley M J N, Park R. Theoretical stress-strain model for confined concrete. Journal of Structural Engineering, 1988, 114(8): 1804-1826

17. Scott B D. Stress-strain behavior of concrete confined by overlapping hoops at low and high strain ratio rates. Dissertation for the Doctoral Degree. Luleå: Luleå University of Technology, 1989

18. Zhou S, Rabczuk T, Zhuang X. Phase field modeling of quasi-static and dynamic crack propagation: Comsol implementation and case studies. Advances in Engineering Software, 2018, 122: 31-49

19. Zhou S, Zhuang X, Rabczuk T. A phase-field modeling approach of fracture propagation in poroelastic media. Engineering Geology, 2018, 240: 189-203

20. Zhou S, Zhuang X, Zhu H, Rabczuk T. Phase field modelling of crack propagation, branching and coalescence in rocks. Theoretical and Applied Fracture Mechanics, 2018, 96: 174-192

21. Zhou S, Zhuang X, Rabczuk T. Phase-field modeling of fluid-driven dynamic cracking in porous media. Computer Methods in Applied Mechanics and Engineering, 2019, 350: 169-198

22. Zhou S, Zhuang X, Rabczuk T. Phase field modeling of brittle compressive-shear fractures in rock-like materials: A new driving force and a hybrid formulation. Computer Methods in Applied Mechanics and Engineering, 2019, 355: 729-752
23. Willam K J. Constitutive model for the triaxial behaviour of concrete. In: IABSE Seminar on Concrete Structure Subjected Triaxial. Zurich, 1975, 19: 1-30

24. Mazars J, Pijaudier-Cabot G. Continuum damage theory-Application to concrete. Journal of Engineering Mechanics, 1989, 115(2): 345-365

25. Pramono E, Willam K. Implicit integration of composite yield surfaces with corners. Engineering Computations, 1989, 6(3): 186197

26. Etse G, Willam K. Fracture energy formulation for inelastic behavior of plain concrete. Journal of Engineering Mechanics, 1994, 120(9): 1983-2011

27. Pivonka P. Constitutive modeling of triaxially loaded concrete considering large compressive stresses: Application to pull-out tests of anchor bolts. Dissertation for the Doctoral Degree. Vienna: Technical University of Vienna, 2001

28. Tao X, Phillips D V. A simplified isotropic damage model for concrete under bi-axial stress states. Cement and Concrete Composites, 2005, 27(6): 716-726

29. Grassl P, Jirásek M. Damage-plastic model for concrete failure. International Journal of Solids and Structures, 2006, 43(22-23): 7166-7196

30. Papanikolaou V K, Kappos A J. Confinement-sensitive plasticity constitutive model for concrete in triaxial compression. International Journal of Solids and Structures, 2007, 44(21): 7021-7048

31. Hognestad E. Study of Combined Bending and Axial Load in Reinforced Concrete Members. Technical Report. University of Illinois at Urbana Champaign, 1951

32. Thorenfeldt E. Mechanical properties of high-strength concrete and applications in design. In: Symposium Proceedings, Utilization of High-Strength Concrete. Norway, 1987

33. Tsai W T. Uniaxial compressional stress-strain relation of concrete. Journal of Structural Engineering, 1988, 114(9): 2133-2136

34. Roy H, Sozen M A. Ductility of concrete. ACI Special Publications, 1965, 12: 213-235

35. Park R, Paulay T. Reinforced concrete structures. John Wiley \& Sons, 1975.

36. Park R, Priestley M J N, Gill W D. Ductility of square-confined concrete columns. Journal of the Structural Division, 1982, 108(4): 929-950

37. Sheikh S A, Uzumeri S M. Analytical model for concrete confinement in tied columns. Journal of the Structural Division, 1982, 108(12): 2703-2722

38. Yong Y K, Nour M G, Nawy E G. Behavior of laterally confined high-strength concrete under axial loads. Journal of Structural Engineering, 1988, 114(2): 332-351

39. Esmaeily A, Xiao Y. Seismic Behavior of Bridge Columns Subjected to Various Loading Patterns. California: Pacific Earthquake Engineering Research Center, University of California, 2002

40. Bićanić N, Zienkiewicz O C. Constitutive model for concrete under dynamic loading. Earthquake Engineering \& Structural Dynamics, 1983, 11(5): 689-710

41. Perzyna P. Fundamental problems in viscoplasticity. Advances in Applied Mechanics, 1966, 9: 243-377

42. Suaris W, Shah S P. Constitutive model for dynamic loading of concrete. Journal of Structural Engineering, 1985, 111(3): 563-576 
43. Rabczuk T, Eibl J. Modelling dynamic failure of concrete with meshfree methods. International Journal of Impact Engineering, 2006, 32(11): 1878-1897

44. Sima J F, Roca P, Molins C. Cyclic constitutive model for concrete. Engineering Structures, 2008, 30(3): 695-706

45. He W, Wu Y F, Liew K M. A fracture energy based constitutive model for the analysis of reinforced concrete structures under cyclic loading. Computer Methods in Applied Mechanics and Engineering, 2008, 197(51-52): 4745-4762

46. Tasnimi A A, Lavasani H H. Uniaxial constitutive law for structural concrete members under monotonic and cyclic loads. Scientia Iranica, 2011, 18(2): 150-162

47. Breccolotti M, Bonfigli M F, D’Alessandro A, Materazzi A L. Constitutive modeling of plain concrete subjected to cyclic uniaxial compressive loading. Construction \& Building Materials, 2015, 94: $172-180$

48. Moharrami M, Koutromanos I. Triaxial constitutive model for concrete under cyclic loading. Journal of Structural Engineering, 2016, 142(7): 04016039

49. Huguet M, Erlicher S, Kotronis P, Voldoire F. Stress resultant nonlinear constitutive model for cracked reinforced concrete panels. Engineering Fracture Mechanics, 2017, 176: 375-405

50. Rabczuk T, Belytschko T. Cracking particles: A simplified meshfree method for arbitrary evolving cracks. International Journal for Numerical Methods in Engineering, 2004, 61(13): 2316-2343

51. Rabczuk T, Belytschko T. A three-dimensional large deformation meshfree method for arbitrary evolving cracks. Computer Methods in Applied Mechanics and Engineering, 2007, 196(29-30): 27772799

52. Rabczuk T, Zi G, Bordas S, Nguyen-Xuan H. A geometrically nonlinear three-dimensional cohesive crack method for reinforced concrete structures. Engineering Fracture Mechanics, 2008, 75(16): $4740-4758$

53. Rabczuk T, Zi G, Bordas S, Nguyen-Xuan H. A simple and robust three-dimensional cracking-particle method without enrichment. Computer Methods in Applied Mechanics and Engineering, 2010, 199(37-40): 2437-2455

54. Rabczuk T, Ren H. A peridynamics formulation for quasi-static fracture and contact in rock. Engineering Geology, 2017, 225: 4248

55. Ren H, Zhuang X, Cai Y, Rabczuk T. Dual-horizon peridynamics. International Journal for Numerical Methods in Engineering, 2016, 108(12): 1451-1476

56. Badnava H, Msekh M A, Etemadi E, Rabczuk T. An $h$-adaptive thermo-mechanical phase field model for fracture. Finite Elements in Analysis and Design, 2018, 138: 31-47

57. Zhang Y, Zhuang X. Cracking elements: A self-propagating strong discontinuity embedded approach for quasi-brittle fracture. Finite Elements in Analysis and Design, 2018, 144: 84-100

58. Zhang Y, Zhuang X. Cracking elements method for dynamic brittle fracture. Theoretical and Applied Fracture Mechanics, 2019, 102: $1-9$

59. Zhang Y, Lackner R, Zeiml M, Mang H A. Strong discontinuity embedded approach with standard SOS formulation: Element formulation, energy-based crack-tracking strategy, and validations. Computer Methods in Applied Mechanics and Engineering, 2015, 287: 335-366

60. Lee J, Fenves G L. Plastic-damage model for cyclic loading of concrete structures. Journal of Engineering Mechanics, 1998, 124(8): 892-900

61. Grassl P, Xenos D, Nyström U, Rempling R, Gylltoft K. CDPM2: A damage-plasticity approach to modelling the failure of concrete. International Journal of Solids and Structures, 2013, 50(24): 38053816

62. Zreid I, Kaliske M. A gradient enhanced plasticity-damage microplane model for concrete. Journal of Computational Mechanics, 2018, 62(5): 1239-1257

63. Unteregger D, Fuchs B, Hofstetter G. A damage plasticity model for different types of intact rock. International Journal of Rock Mechanics and Mining Sciences, 2015, 80: 402-411

64. Oller S. A continuous damage model for frictional materials. Dissertation for the Doctoral Degree. Barcelona: Technical University of Catalonia, 1988 (In Spanish)

65. Valentini B. A three-dimensional constitutive model for concrete and its application to large scale finite element analyses. Dissertation for the Doctoral Degree. Innsbruck: University of Innsbruck, 2011

66. Gopalaratnam V S, Shah S P. Softening response of plain concrete in direct tension. ACI Journal Proceedings, 1985, 82(3): 310-323

67. Karsan I D, Jirsa J O. Behavior of concrete under compressive loadings. Journal of the Structural Division, 1969, 95: 2543-2563

68. Van Mier J G M. Strain-softening of concrete under multiaxial loading conditions. Dissertation for the Doctoral Degree. Lausanne: Technical University of Eindhoven, 1984

69. Taerwe L, Matthys S. Fib Model Code for Concrete Structures 2010. Ernst \& Sohn, Wiley, 2013

70. Kupfer H, Hilsdorf H K, Rusch H. Behavior of concrete under biaxial stresses. ACI Journal Proceedings, 1969, 66(8): 656-666

71. Imran I, Pantazopoulou S J. Experimental study of plain concrete under triaxial stress. ACI Materials Journal, 1996, 93(6): 589-601

72. Reinhardt H W, Cornelissen H A W, Hordijk D A. Tensile tests and failure analysis of concrete. Journal of Structural Engineering, 1986, 112(11): 2462-2477

73. ABAQUS v6.14 Documentation. Dassault Systèmes Simulia Corporation, 2014

74. Azadi Kakavand M R, Neuner M, Schreter M, Hofstetter G. A 3D continuum FE-model for predicting the nonlinear response and failure modes of RC frames in pushover analyses. Bulletin of Earthquake Engineering, 2018, 16(10): 4893-4917

75. Azadi Kakavand M R, Taciroglu E, Hofstetter E. Predicting the nonlinear response and damage patterns of bare and infilled reinforced concrete frames using $3 \mathrm{D}$ finite element models. In: Proceedings of 16th D-A-CH Conference on Earthquake Engineering and Structural Dynamics (D-A-CH 2019). Innsbruck: University of Innsbruck, 2019

76. Azadi Kakavand M R, Sezen H, Taciroglu E. Rectangular Column Database. DesignSafe-CI, 2019

77. Azadi Kakavand M R, Sezen H, Taciroglu E. Circular Column Database. DesignSafe-CI, 2019 